\title{
The impact of incidental durotomy on the outcome of decompression surgery in degenerative lumbar spinal canal stenosis: analysis of the Lumbar Spinal Outcome Study (LSOS) data-a Swiss prospective multi-center cohort study
}

Nils H. Ulrich ${ }^{1,3^{*}}$, Jakob M. Burgstaller ${ }^{1 \dagger}$, Florian Brunner ${ }^{2}$, François Porchet ${ }^{3}$, Mazda Farshad ${ }^{2}$, Giuseppe Pichierri ${ }^{1}$, Johann Steurer ${ }^{1}$, Ulrike Held ${ }^{1}$ and on behalf of the LSOS Study Group

\begin{abstract}
Background: Incidental durotomy is a well-known complication during surgery for degenerative lumbar spinal stenosis (DLSS). In this prospective multicenter cohort study including eight medical centers our aim was to assess whether incidental durotomy during first-time lumbar spinal stenosis decompression surgery without fusion has an impact on long-term outcome.
\end{abstract}

Methods: Patients of the multi-center Lumbar Stenosis Outcome Study (LSOS) with confirmed DLSS undergoing firsttime decompression without fusion were enrolled in this study. Baseline patient characteristics and outcomes were analyzed at 6, 12, and 24 months follow-up respectively with the Spinal Stenosis Measure (SSM), the Numeric Rating Scale (NRS), Feeling Thermometer (FT), the EQ-5D-EL, and the Roland and Morris Disability Questionnaire (RMDQ).

Results: A total of 167 patients met the inclusion criteria. Fifteen (9\%) of those patients had an incidental durotomy. Baseline characteristics were similar between the durotomy and no-durotomy group. All patients improved over time. In the group of durotomy patients, the median improvement in SSM symptoms scale was 1.1 points at 6 months, 1.1 points at 12 months, and 1.6 points at 24 months after baseline. For the no-durotomy group, these improvements were $0.8,0.9$, and 0.9. For SSM function the improvements were 1.0, 0.8 , and 0.9 in the durotomy group, and 0.6, 0.8, and 0.8 in the no-durotomy group. None of the between-group differences were statistically significant.

Conclusions: Incidental durotomy in patients with DLSS undergoing first-time decompression surgery without fusion did not have negative effect on long-term outcome and quality of life. However, only 15 patients were included in the durotomy group but these findings remained even after adjusting for observed differences in baseline characteristics.

Keywords: Durotomy, Dural tear, Decompression, Degenerative lumbar spinal stenosis, Multi-center, Surgery

\footnotetext{
* Correspondence: nils.hb.ulrich@gmail.com

${ }^{\dagger}$ Equal contributors

${ }^{1}$ Horten Centre for Patient Oriented Research and Knowledge Transfer,

University of Zurich, Pestalozzistr. 24, 8091 Zürich, Switzerland

${ }^{3}$ Department of Orthopedics and Neurosurgery, Spine Center, Schulthess

Clinic, Zurich, Switzerland

Full list of author information is available at the end of the article
}

\section{$\int$ Biomed Central}

C 2016 Ulrich et al. Open Access This article is distributed under the terms of the Creative Commons Attribution 4.0 International License (http://creativecommons.org/licenses/by/4.0/, which permits unrestricted use, distribution, and reproduction in any medium, provided you give appropriate credit to the original author(s) and the source, provide a link to the Creative Commons license, and indicate if changes were made. The Creative Commons Public Domain Dedication waiver (http://creativecommons.org/publicdomain/zero/1.0/) applies to the data made available in this article, unless otherwise stated. 


\section{Background}

Incidental durotomy is a potential complication of lumbar spinal surgery. Its incidence is reported to be up to $17 \%$ depending on the literature reviewed [1-14]. Furthermore, it is well known that the type of surgical procedure performed, reoperations, and older age increase the risk of incidental durotomy $[3-6,9,15,16]$.

Persistent dural tears may cause various sequelae such as headache, meningeal pseudocyst formation, or dural cutaneous cerebrospinal fluid fistulas leading to meningitis and arachnoiditis [3, 12]. Recommendations to prevent these sequelae are primary repair, bed rest, and lumbar drain placement $[3,9,14]$.

Currently, the impact of successfully treated dural tears on long-term outcomes is still controversial. One publication issued in 2005 demonstrated an association with poor clinical outcome in patients undergoing lumbar disc surgery [12] whereas other studies found no long-term sequelae in patients undergoing spinal surgery [3, 6, 9, 17]. However, long-term effects for decompression surgery only without fusion specifically for degenerative lumbar spinal stenosis (DLSS) have not been studied so far. Lumbar spinal stenosis is the most frequent indication for spine surgery in patients older than 65 years [18]. For instance, in the metropolitan area of Zurich with around 1.3 million inhabitants almost 1000 lumbar decompression surgeries without fusions in patients with DLSS are performed every year [19].

The purpose of this study was to assess whether incidental durotomy during first-time decompression surgery without fusion for degenerative lumbar spinal stenosis had an impact on long-term outcomes. We used data from the Lumbar Stenosis Outcome Study (LSOS) [20], a multi-center prospective cohort study, to explore this issue.

\section{Methods}

\section{Patient selection}

Patients with a history of neurogenic claudication were recruited from outpatient clinics at all participating centers. Eligible patients had no evidence of stenosis caused by tumor, fracture, infection, or significant deformity ( $>15^{\circ}$ lumbar scoliosis), and were aged 50 years or more. Magnetic Resonance Imaging (MRI) verified lumbar spinal canal stenosis. None of the patients had prior lumbar spine surgery. Furthermore, patients had no clinical peripheral artery occlusive disease (confirmed by a vascular specialist in patients without palpable pulses in the lower limb).

\section{Surgical procedure}

Surgery consisted of a standard open posterior lumbar laminectomy or laminotomy at the affected level or levels without instrumentation. Decompression of the lateral recessus and foramina was performed when necessary to decompress the local nerve roots.

\section{Radiological classification}

The MRI of each patient was evaluated by a senior radiologist. He categorized the severity of the stenosis (central, lateral recess, and neural foraminal) of each level into "no", "mild", "moderate", or "severe" according to the consensus paper on core radiological parameters of the LSOS-study [21].

\section{Data collection and follow-up}

Parts of the basic data sheet were interviewadministered and recorded by a study coordinator. All other questionnaires were self-administered and completed by the patients themselves. All data were collected at baseline, and at 6 months. Long-term outcome data was gathered after 1 and 2 years.

\section{Questionnaires}

\section{Spinal Stenosis Measure (SSM)}

The SSM, an instrument specifically developed for spinal stenosis patients by Stucki et al. [22], targets to measure severity of symptoms and quantifies disability of the lumbar spinal stenosis population. It is recommended by the North American Spine Society (NASS) and used in different studies on lumbar spinal stenosis [23-26]. It consists of three different subscales; the symptom severity subscale, the physical function subscale and the satisfaction subscale. The symptom severity scale can be divided into a pain domain (severity, frequency and back pain) and a neuroischemic domain (leg pain, weakness, numbness and balance disturbance). Score range is from 1 to 5 and 1 to 4 (best-worst).

\section{Feeling Thermometer (FT) and Numeric Rating Scale (NRS)}

General assessment of lumbar spinal stenosis symptoms such as lower extremity pain and discomfort are measured. Score range is from 0 to 100 and 0 to 10 (best-worst).

EQ-5D-3L: The EQ-5D-3L is an assessment tool to measure health-related quality of life. It measures general non-disease specific health-related quality of life, including physical, mental and social dimensions [27]. The health status measures five dimensions of health (mobility, self-care, usual activities, pain/discomfort and anxietycpdepression) which can be calculated as a sum score (score range 0-100, worst-best) [27]. The second part of the questionnaire estimates patient's actual health status (score range 0-100, worst-best). 
Roland and Morris Disability Questionnaire (RMDQ)

The Roland and Morris Disability Questionnaire is a back pain specific, self-rated physical disability questionnaire developed by Roland and Morris in 1983 [28]. Disability is measured respective to the following categories: physical function activities and activities of daily living including eating and sleeping. Score range is from 0 to 24 (bestworst).

\section{Cumulative Illness Rating Scale (CIRS)}

Comorbidity is measured using CIRS that rates the presence and severity of comorbid diseases in 14 organ systems (according to modified version by Miller et al. [29]). Score range is from 0 to 56 (best-worst).

\section{Hospital Anxiety and Depression Scale (HADS)}

The HADS was originally developed to measure anxiety and depression in a hospital setting [30], however, it is nowadays common to use it in all settings [31]. It contains two 7-item subscales for anxiety and depression with a score range of 0-21 (best-worst) each.

\section{Outcomes}

Main outcomes were changes in SSM symptoms and function, NRS, FT, EQ-5D-EL sum score and actual health status, and RMDQ between the durotomy and no-durotomy group.

\section{Statistical analyses}

Analysis of data consisted of descriptive statistics of patient demographics and outcomes. Continuous variables were shown as median and interquartile ranges and categorical variables were shown as numbers and percentages of total. To evaluate differences between patients of the durotomy and no-durotomy groups, we used Wilcoxon tests for the continuous variables and chi-squared tests for the categorical variables. We calculated changes from baseline at 6 months, 12 months, and 24 months for the main outcome variables SSM symptoms and function, NRS, FT, EQ-5D-EL sum score and actual health status, and RMDQ. To assess whether these changes differed significantly across the durotomy versus no-durotomy group, we used Wilcoxon tests. In order to reduce the probability of false positive findings, we used Bonferroni adjustment of the global significance level $\alpha=0.05$. The number of statistical tests was 50 , therefore the new significance level $\alpha^{*}=0.05 / 50=0.001$. If there are differences between the baseline characteristics in the durotomy and the no-durotomy groups, we will adjust for these baseline characteristics for changes in long term outcomes using multiple linear regression models with durotomy (yes/no) as the determinant.
For graphical representations of SSM symptoms and function, and EQ-5D-EL sum score and actual health status over time, boxplots were used.

All analyses were conducted with $\mathrm{R}$ for Windows [32].

\section{Results}

\section{Patient characteristics}

Table 1 presents the patients characteristics at baseline. A total of 167 patients met the inclusion criteria; in 15 of these, a durotomy occurred (prevalence: $9 \%$ ). There were no significant differences in any of the baseline characteristics. Overall, 88 of 167 patients (52.7 \%) were female, median age was 75 years (IQR 12), and median body mass index was $26.3 \mathrm{~kg} / \mathrm{m}^{2}$ (IQR 6.1 ). Of the study population 104 (62.3\%) patients hold higher education degree (no university) and 27 (16.2 \%) hold a university degree. Seven patients (46.7 \%) had previous lumbar epidural steroid injections in the durotomy group, and 84 patients $(55.3 \%)$ in the no-durotomy group. There were also no statistically significant differences in all questionnaires.

Table 1 Patient characteristics

\begin{tabular}{|c|c|c|c|}
\hline Characteristics & $\begin{array}{l}\text { Durotomy } \\
(n=15)\end{array}$ & $\begin{array}{l}\text { No durotomy } \\
(n=152)\end{array}$ & $p$ \\
\hline Age, median (IQR), y & $73(11)$ & $75(12)$ & 0.61 \\
\hline Female, n (\%) & $6(40)$ & $82(53.9)$ & 0.45 \\
\hline BMI, median (IQR), kg/m2 & $26(8.2)$ & $26.3(5.8)$ & 0.82 \\
\hline Diabetes mellitus, n (\%) & $16(10.5)$ & $2(13.3)$ & 0.99 \\
\hline Smoker, n (\%) & $1(6.7)$ & $13(8.6)$ & 0.69 \\
\hline Level of education & & & 0.10 \\
\hline $\begin{array}{l}\text { Compulsory education ( } 1-9 \text { years), } \\
n(\%)\end{array}$ & $4(26.7)$ & $32(21.1)$ & \\
\hline $\begin{array}{l}\text { Higher education/vocational training } \\
\text { (no university) (10-12 years), } n(\%)\end{array}$ & $6(40)$ & $98(64.5)$ & \\
\hline University degree, $n(\%)$ & $5(33.3)$ & $22(14.5)$ & \\
\hline CIRS, median (IQR) & $7(5.5)$ & $9(4.5)$ & 0.15 \\
\hline HADS anxiety, median (IQR) & $2(3.5)$ & $4(4)$ & 0.06 \\
\hline HADS depression, median (IQR) & $3(3)$ & $4(4.5)$ & 0.13 \\
\hline SSM symptoms, median (IQR) & $3.1(0.5)$ & $3.1(1)$ & 0.84 \\
\hline SSM functions, median (IQR) & $2(0.8)$ & $2.4(1)$ & 0.21 \\
\hline NRS, median (IQR) & $6(1.5)$ & $7(3)$ & 0.76 \\
\hline Feeling thermometer, median (IQR) & $70(22.5)$ & $70(30)$ & 0.90 \\
\hline EQ-5D-EL sum score, median (IQR) & $70(25)$ & $70(20)$ & 0.99 \\
\hline $\begin{array}{l}\text { EQ-5D-EL actual health status, } \\
\text { median (IQR) }\end{array}$ & $80(34)$ & $65(40)$ & 0.19 \\
\hline RMDQ, median (IQR) & $14(8)$ & $13(8)$ & 0.64 \\
\hline $\begin{array}{l}\text { Prior lumbar epidural steroid injection, } \\
\mathrm{n}(\%)\end{array}$ & $7(46.7)$ & $84(55.3)$ & 0.71 \\
\hline
\end{tabular}

BMI body mass index, CIRS cumulative illness rating scale, FT feeling thermometer, HADS hospital anxiety and depression scale, IQR interquartile range, NRS numeric rating scale (NRS), RMDQ Roland and Morris disability questionnaire, SSM spinal stenosis measure 


\section{Surgical characteristics}

There were no significant differences between the durotomy and no-durotomy group in decompression levels, and in the number of decompressed levels. In both groups, around $80 \%$ of the patients were operated microscopically (Table 2).

$40.0 \%$ of the patients in the durotomy and $23.7 \%$ in the no-durotomy group had three or more severe stenotic levels whereas 46.7 and $63.2 \%$, respectively, had three or more mild or moderate stenotic levels. Neither was statistically significant.

\section{Surgical management of durotomy}

All 15 patients experienced incidental durotomy during surgery were successfully treated intraoperatively. In nine patients $(60 \%)$ the durotomy was firstly sutured, afterwards either a patch and/or glue was applied. Two patients $(13 \%)$ only received a patch, in one patient (7\%) only glue was applied, and in the remaining three

Table 2 Comparison of perioperative outcomes and radiological parameters between the durotomy and no-durotomy group

\begin{tabular}{|c|c|c|c|}
\hline Outcome & $\begin{array}{l}\text { Durotomy } \\
(n=15)\end{array}$ & $\begin{array}{l}\text { No durotomy } \\
(n=152)\end{array}$ & $p$ \\
\hline \multicolumn{4}{|l|}{ Decompression level, n (\%) } \\
\hline $\mathrm{L} 1 / \mathrm{L} 2$ & $1(6.7)$ & $4(2.6)$ & 0.94 \\
\hline L2/L3 & $6(40.0)$ & $35(23.0)$ & 0.25 \\
\hline $\mathrm{L} 3 / \mathrm{L} 4$ & $10(66.7)$ & $99(65.1)$ & 0.99 \\
\hline$\llcorner 4 / L 5$ & $11(73.3)$ & $126(82.9)$ & 0.57 \\
\hline L5/S1 & $2(13.3)$ & $27(17.8)$ & 0.94 \\
\hline Levels decompressed, n (\%) & & & 0.49 \\
\hline 1 & $5(33.3)$ & $50(32.9)$ & \\
\hline 2 & $5(33.3)$ & $70(46.1)$ & \\
\hline$\geq 3$ & $5(33.3)$ & $32(21.1)$ & \\
\hline OP technique, n (\%) & & & 0.90 \\
\hline Conventional & $2(13.3)$ & $23(15.1)$ & \\
\hline Microscopic & $12(80.0)$ & $123(80.9)$ & \\
\hline No. of severe stenotic levels, n (\%) & & & 0.57 \\
\hline $0^{\mathrm{a}}$ & $1(6.7)$ & $11(7.2)$ & \\
\hline 1 & $4(26.7)$ & $48(31.6)$ & \\
\hline 2 & $4(26.7)$ & $57(37.5)$ & \\
\hline$\geq 3$ & $6(40.0)$ & $36(23.7)$ & \\
\hline $\begin{array}{l}\text { No. of mild/moderate stenotic levels, } \\
\text { n (\%) }\end{array}$ & & & 0.63 \\
\hline $0^{b}$ & $1(6.7)$ & $5(3.2)$ & \\
\hline 1 & $2(13.3)$ & $13(8.6)$ & \\
\hline 2 & $5(33.3)$ & $38(25.0)$ & \\
\hline$\geq 3$ & $7(46.7)$ & $96(63.2)$ & \\
\hline
\end{tabular}

${ }^{a}$ No severe stenotic levels

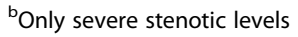

patients $(20 \%)$ a patch and glue were applied. No lumbar drain was placed.

\section{Intra- and postoperative complications}

Only one patient $(0.7 \%)$ in the no-durotomy group experienced a prominent epidural bleeding due to a large epidural venous plexus during surgery, that led to revision surgery on the next day (Table 3 ). Postoperative wound infection occurred in one patient $(6.7 \%)$ in the durotomy group, and in two patients (1.3\%) in the nodurotomy group. Other postoperative complications (e.g., urosepsis, hemorrhage, wound healing deficit) were seen in 20.0 and $10.5 \%$ of the patients, respectively. None of these differences were statistically significant. Furthermore, no patient died within 3 months postoperatively.

\section{Changes in main outcomes from baseline to 6 months, 12 months, and 24 months}

All patients improved over time. In the group of durotomy patients, the median improvement was 1.1 points at 6 months, 1.1 points at 12 months, and 1.6 points at 24 months after baseline in SSM symptoms scale. For the no-durotomy group, these improvements were $0.8,0.9$, and 0.9. For SSM function the improvements were 1.0, 0.8 , and 0.9 in the durotomy group, and $0.6,0.8$, and 0.8 in the no-durotomy group. The corresponding changes over time for the other questionnaires can be found in Table 4. None of the group differences between the nodurotomy and the durotomy group were statistically significant. Lack of statistically significant differences in the baseline characteristics could be due to the unequal size of the durotomy and the no-durotomy groups. Studying the baseline characteristics apart from $p$-values, the variables age, gender, higher education, HADS anxiety, and EQ-5D-EL actual health status seemed to make the groups not directly comparable. Therefore, we fitted multiple linear regression models to the long term outcomes,

Table 3 Intra- and postoperative complications

\begin{tabular}{|c|c|c|c|}
\hline Outcome & $\begin{array}{l}\text { Durotomy } \\
(n=15)\end{array}$ & $\begin{array}{l}\text { No durotomy } \\
(n=152)\end{array}$ & $p$ \\
\hline \multicolumn{4}{|l|}{ Intraoperative complications, n (\%) } \\
\hline Epidural venous bleeding & $0(0)$ & $1(0.7)$ & 0.99 \\
\hline Other & $0(0)$ & $0(0)$ & \\
\hline None & $15(100)$ & $151(99.3)$ & \\
\hline \multicolumn{4}{|l|}{ Postoperative complications, $n$ (\%) } \\
\hline Wound infection & $1(6.7)$ & $2(1.3)$ & 0.60 \\
\hline Other & $3(20.0)$ & $16(10.5)$ & 0.99 \\
\hline None & $11(73.3)$ & $134(88.2)$ & \\
\hline $\begin{array}{l}\text { postoperative mortality (death within } \\
6 \text { weeks of surgery), } n(\%)\end{array}$ & $0(0)$ & $0(0)$ & \\
\hline $\begin{array}{l}\text { postoperative mortality (death within } \\
3 \text { months of surgery), } \mathrm{n}(\%)\end{array}$ & $0(0)$ & $0(0)$ & \\
\hline
\end{tabular}


Table 4 Changes in main outcomes from baseline to 6, 12, and 24 months: median (IQR)

\begin{tabular}{|c|c|c|c|c|c|c|c|c|c|}
\hline \multirow[t]{2}{*}{ Outcome } & \multicolumn{3}{|c|}{ Baseline - 6 months } & \multicolumn{3}{|c|}{ Baseline -12 months } & \multicolumn{3}{|c|}{ Baseline - 24 months } \\
\hline & Durotomy & No durotomy & $p$ & Durotomy & No durotomy & $p$ & Durotomy & No durotomy & $p$ \\
\hline$\Delta$ SSM symptoms & $1.1(0.9)$ & $0.8(1.3)$ & 0.02 & $1.1(0.8)$ & $0.9(1)$ & 0.19 & $1.6(0.9)$ & $0.9(1)$ & 0.13 \\
\hline$\Delta \mathrm{SSM}$ function & $1(0.4)$ & $0.6(1)$ & 0.12 & $0.8(0.6)$ & $0.8(1)$ & 0.53 & $0.9(0.6)$ & $0.8(1.1)$ & 0.48 \\
\hline$\Delta \mathrm{NRS}$ & $4(2.5)$ & $3(4)$ & 0.13 & $4(2.5)$ & $3(4)$ & 0.24 & $5(1.8)$ & $4(4.2)$ & 0.22 \\
\hline$\Delta \mathrm{FT}$ & $45(28.5)$ & $30(40)$ & 0.08 & $45(29)$ & $34.5(48.2)$ & 0.2 & $60(16.2)$ & $34(39.5)$ & 0.06 \\
\hline$\Delta$ EQ-5D-EL sum score & $-20(25)$ & $-10(30)$ & 0.04 & $-20(20)$ & $-20(30)$ & 0.17 & $-20(17.5)$ & $-15(30)$ & 0.45 \\
\hline$\Delta \mathrm{EQ}-5 \mathrm{D}-\mathrm{EL}$ ahs & $-9(29.5)$ & $-10(33.5)$ & 0.97 & $-5.5(28.8)$ & $-10(37.5)$ & 0.83 & $-6.5(14)$ & $-10(35.5)$ & 0.42 \\
\hline$\Delta \mathrm{RMDQ}$ & $6(7)$ & $3(6)$ & 0.03 & $8(5)$ & $4(7)$ & 0.01 & $9.5(9)$ & $4(8)$ & 0.02 \\
\hline
\end{tabular}

Ahs actual health status, FT feeling thermometer, NRS numeric rating scale (NRS), RMDQ Roland and Morris disability questionnaire, SSM spinal stenosis measure Numbers of patients: Baseline -6 months: 15 patients in the durotomy group, 152 patients in the no durotomy group. No missing values. Baseline - 12 months, 15 patients in the durotomy group, 152 patients in the no durotomy group. No missing values in SSM subscales, single missing values in some secondary outcomes. Baseline - 24 months, 11 patients in the durotomy group, 90 patients in the no durotomy group for SSM subscales. Single missing values in some outcomes

and estimated the effect of durotomy, adjusted for the above mentioned variables simultaneously. It turned out that the estimated adjusted effects were of the same size as the unadjusted changes presented in Table 4, and none of these were statistically significant either.

However, the durotomy group experienced greater improvements in all scales at all follow-up points except in the EQ-5D-EL actual heath status than the nodurotomy group.

Figure 1 shows SSM symptoms and function, EQ-5D-EL sum score and actual health status over time with boxplots.

\section{Discussion}

In this study we investigated 167 consecutive patients with symptomatic degenerative lumbar spinal canal stenosis undergoing lumbar decompression surgery without fusion. Of these, 15 patients (9\%) experienced incidental durotomy during surgery. We assessed changes in the outcomes Spinal Stenosis Measure (SSM), the Numeric Rating Scale (NRS), Feeling Thermometer (FT), the EQ-5D-EL, and the Roland and Morris Disability Questionnaire (RMDQ) over time. Patients with and without incidental durotomy improved from baseline to 24 months of follow-up. Comparing the improvements between the groups, we found greater improvement in the durotomy-group but the difference was not statistically significant. The results of our study indicate that incidental durotomy followed by appropriate repair measures has no negative effect on the above described outcomes.

Other studies analyzed the impact of incidental durotomy on outcomes and reported conflicting results. Desai et al. [17] showed that dural tears did not have any negative impact on outcome in their multi-center study with 409 patients and 37 cases of incidental durotomy. Wang et al. [9] reported in a series of 88 patients with durotomy that incidental durotomy did not compromise long-term outcome if treated appropriately.
Furthermore, Grannum et al. [10] demonstrated in a case-control study that incidental durotomy was not associated with less improvement over time. Recent data from Stromqvist et al. [33] showed that dural tears did not compromise the results of discectomy at 1 year post-surgery. Cammisa et al. [3] came to similar conclusions in their study of 66 patients with incidental durotomies. All previous studies were based on retrospectively collected data, except the publications by Desai et al. [17] and Grannum et al. [10] Furthermore, they included patients who underwent different spine procedures such as lumbar discectomies, fusion surgeries, and revision surgeries.

In contrast to the above mentioned studies, Saxler et al. [12] reported a tendency for persisting back pain, higher number of re-operations, and longer duration of inability to work in a group of 41 patients with incidental durotomy after lumbar discectomy as compared with 41 appropriately matched patients without dural tears. These results are not easily comparable to our findings because the indication for surgery was quite different.

The prevalence of dural tears in our study was $9 \%$. This rate is comparable to that reported for lumbar spine surgery in other large series $[3,6,9,14,17,34]$. Different patient characteristics like gender, age and severity of stenosis, as well as experience of the surgeon and surgical procedure may attribute to a certain variation across studies (1-17\%).

Most common complications associated with durotomies include headache, wound infection, meningeal pseudocyst formation, or dural cutaneous cerebrospinal fluid fistulas leading to meningitis and arachnoiditis $[3,12]$. In the present study we did not observe a higher incidence of intraoperative vascular injury, or postoperative wound infection compared to other studies [3, 10, 17]. Furthermore, no neurological complications, cerebrospinal fluid fistula formation, or other surgical complications occurred. 


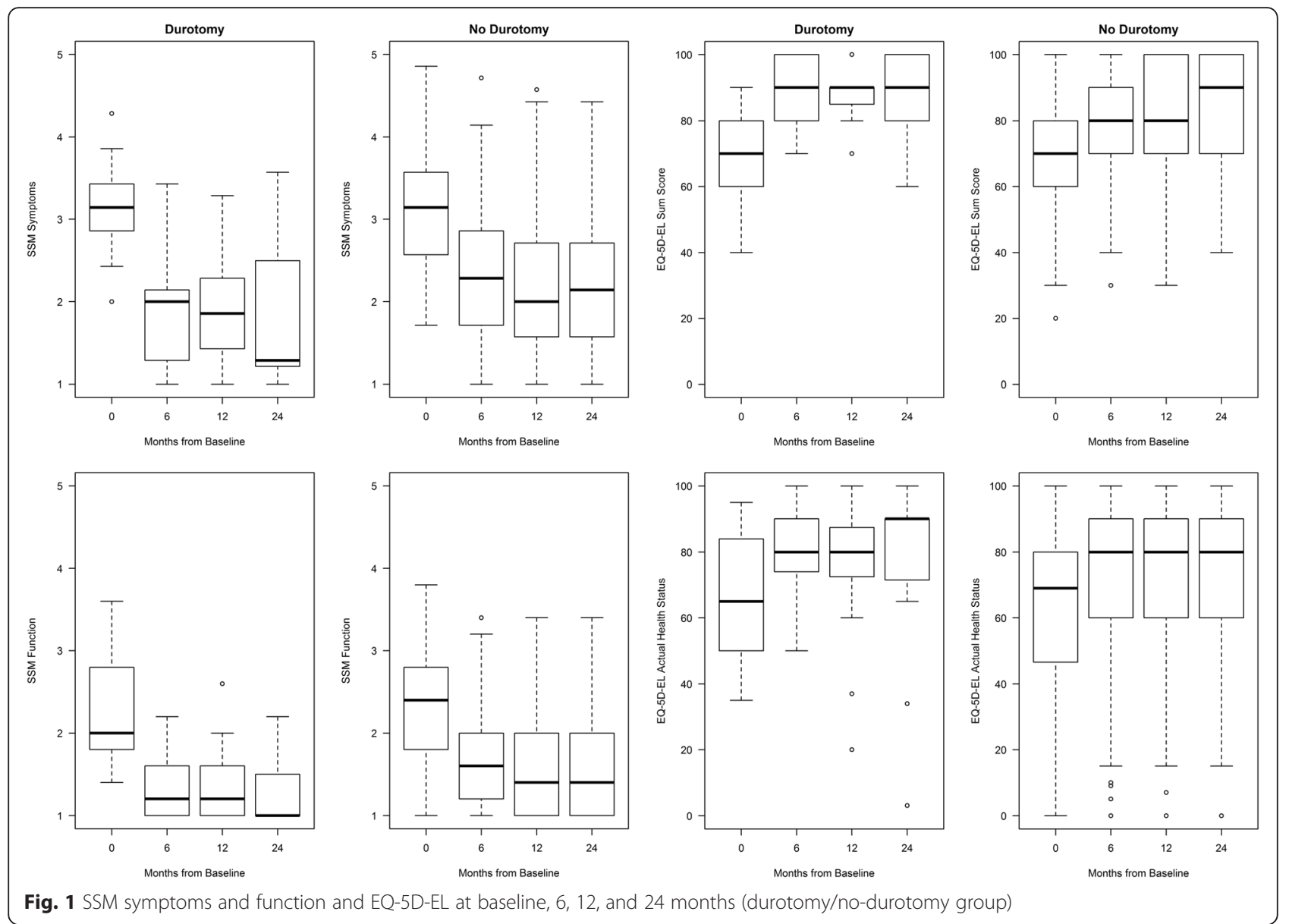

Our study has several strengths. These include the multi-center setting and prospective collection of data, as well as the use of established questionnaires on degenerative lumbar spinal stenosis. Four out of eight study centers are teaching hospitals in which residents assist spine surgeries. Nevertheless, our durotomy prevalence rate was within the range of other studies. Furthermore, our patient sample was very homogenous since only first-time decompression surgeries without fusion were included. In addition to that, the groups of patients with and without incidental durotomy were comparable with respect to their baseline characteristics.

A limitation of our study was the restricted number of 15 patients with durotomy. A higher number of patients with a durotomy would be desirable for future investigations. Furthermore, we did not collect detailed information on the occurrence and duration of postoperative headache, and pseudomeningocele. These are typical complications associated with dural tears $[35,36]$. Postoperative management of incidental durotomy often involves placement of a subarachnoid drain and postoperative bed rest, which can lead to extended hospital stay. The recording of specific treatment modalities and the length of hospital stay was not part of LSOS-study and should be included in future studies.

An unexpected finding of our study was the tendency for better outcomes in the durotomy group as compared to the no-durotomy group. Several other studies investigated preoperative predictors for clinical outcome after lumbar spinal stenosis surgery. Aalto et al. [37] found that depression, cardiovascular comorbidity, and reduced walking ability caused by disorders had an adverse influence on patients' subjective outcomes. In another review article by McKillop et al. [38], preoperative depression was associated with postoperative symptom severity and disability. In our patient sample, the durotomy group had a lower preoperative HADS depression score that could have influenced the better but not statistically significant postoperative outcome in contrast to the no-durotomy group. Another reason for greater improvement in the durotomy group could be the higher number of severe stenotic levels (40\%) in comparison to the nodurotomy group (23\%). Decompression surgery might have been more difficult in patients with a higher number of severe stenotic levels, and thus might increase 
the probability for dural tears. On the other hand, these patients were more likely to benefit from surgery that was ultimately reflected by our outcome measures.

\section{Conclusions}

Incidental durotomy in patients with degenerative lumbar spinal stenosis undergoing first-time decompression surgery without fusion did not have negative effect on long-term outcome and quality of life. However, only 15 patients were included in the durotomy group but these findings remained even after adjusting for observed differences in baseline characteristics.

\section{Ethics}

This multi-center cohort study was conducted in compliance with all international laws and regulations as well as any applicable guidelines. Written informed consent to participate in the study has been obtained from participants. The study was approved by the independent Ethics Committee of the Canton Zurich (KEK-ZH-NR: 2010-0395/0).

\section{Availability of data and materials}

Materials described in the manuscript, including all relevant raw data, is not freely available because LSOS is an ongoing study. All data will be freely available after follow-up time in 2021.

\section{Abbreviations \\ CIRS: cumulative illness rating scale; DLSS: degenerative lumbar spinal stenosis; FT: feeling thermometer; HADS: hospital anxiety and depression scale; IQR: interquartile range; LSOS: lumbar stenosis outcome study; LSS: Iumbar spinal stenosis; MRI: magnetic resonance imaging; NASS: north american spine society; nrs: the numeric rating scale; RMDQ: roland and morris disability questionnaire; SSM: spinal stenosis measure. \\ Competing interests \\ The authors declare that they have no competing interests. \\ Authors' contributions \\ NU wrote the Introduction and Discussion part. JB and UH performed the search, study selection, data extraction and data analyses, and wrote the method and result part. FP and JS wrote the abstract. MF, GP and FB participated in its design and coordination and helped to draft the manuscript. All authors read and approved the final version.}

\section{Acknowledgements}

We thank all the people who participated in the LSOS study.

\section{Funding sources}

The authors thank the Baugarten Foundation, the Helmut Horten Foundation, the Pfizer-Foundation for geriatrics \& research in geriatrics, the Symphasis Charitable Foundation and the OPO Foundation for their support. The investigators of this study have independently initiated the project. The above mentioned foundations had no involvement in study design; in the collection, analysis and interpretation of data; in the writing of the report; or in the decision to submit the article for publication.

\section{Author details}

${ }^{1}$ Horten Centre for Patient Oriented Research and Knowledge Transfer, University of Zurich, Pestalozzistr. 24, 8091 Zürich, Switzerland. ${ }^{2}$ Spine Division, Balgrist University Hospital, University of Zurich, Zürich, Switzerland. ${ }^{3}$ Department of Orthopedics and Neurosurgery, Spine Center, Schulthess Clinic, Zurich, Switzerland.
Received: 28 August 2015 Accepted: 9 April 2016

Published online: 18 April 2016

\section{References}

1. Barrios C, Ahmed M, Arrotegui Jl, Bjornsson A. Clinical Factors Predicting Outcome after Surgery for Herniated Lumbar-Disk - an Epidemiologic Multivariate-Analysis. J Spinal Disord. 1990;3(3):205-9.

2. Black P. Cerebrospinal fluid leaks following spinal surgery: use of fat grafts for prevention and repair - Technical note. J Neurosurg. 2002;96(2):250-2.

3. Cammisa Jr FP, Girardi FP, Sangani PK, Parvataneni HK, Cadag S, Sandhu HS. Incidental durotomy in spine surgery. Spine (Phila Pa 1976). 2000;25(20):2663-7.

4. Eismont FJ, Wiesel SW, Rothman RH. Treatment of Dural Tears Associated with Spinal Surgery. J Bone Joint Surg Am. 1981:63(7):1132-6.

5. Finnegan WJ, Fenlin JM, Marvel JP, Nardini RJ, Rothman RH. Results of surgical intervention in the symptomatic multiply-operated back patient - analysis of 67 cases followed for 3 to 7 years. J Bone Joint Surg Am. 1979;61(7):1077-82.

6. Jones AAM, Stambough JL, Balderston RA, Rothman RH, Booth RE. Longterm results of lumbar spine surgery complicated by unintended incidental durotomy. Spine. 1989:14(4):443-66.

7. Kitchel SH, Eismont FJ, Green BA. Closed subarachnoid drainage for management of cerebrospinal-fluid leakage after an operation on the spine. J Bone Joint Surg Am. 1989;71A(7):984-7.

8. Shaikh S, Chung F, Imarengiaye C, Yung D, Bernstein M. Pain, nausea, vomiting and ocular complications delay discharge following ambulatory microdiscectomy. Can J Anaesth. 2003:50(5):514-8.

9. Wang JC, Bohlman HH, Riew KD. Dural tears secondary to operations on the lumbar spine - Management and results after a two-year-minimum followup of eighty-eight patients. J Bone Joint Surg Am. 1998;80A(12):1728-32.

10. Grannum S, Patel MS, Attar F, Newey M. Dural tears in primary decompressive lumbar surgery. Is primary repair necessary for a good outcome? Eur Spine J. 2014;23(4):904-8

11. Rampersaud YR, Moro ER, Neary MA, White K, Lewis SJ, Massicotte EM, Fehlings MG. Intraoperative adverse events and related postoperative complications in spine surgery: implications for enhancing patient safety founded on evidencebased protocols. Spine (Phila Pa 1976). 2006;31(13):1503-10.

12. Saxler G, Kramer J, Barden B, Kurt A, Pfortner J, Bernsmann K. The long-term clinical sequelae of incidental durotomy in lumbar disc surgery. Spine (Phila Pa 1976). 2005:30(20):2298-302.

13. Smorgick Y, Baker KC, Herkowitz H, Montgomery D, Badve SA, Bachison C, Ericksen S, Fischgrund JS. Predisposing factors for dural tear in patients undergoing lumbar spine surgery. J Neurosurg Spine. 2015;22(5):483-6.

14. Tafazal SI, Sell PJ. Incidental durotomy in lumbar spine surgery: incidence and management. Eur Spine J. 2005:14(3):287-90.

15. Deyo RA, Cherkin DC, Loeser JD, Bigos SJ, Ciol MA. Morbidity and mortality in association with operations on the lumbar spine - the influence of age, diagnosis, and procedure. J Bone Joint Surg Am. 1992;74A(4):536-43.

16. Stolke D, Sollmann WP, Seifert V. Intra- and postoperative complications in lumbar disc surgery. Spine (Phila Pa 1976). 1989;14(1):56-9.

17. Desai A, Ball PA, Bekelis K, Lurie J, Mirza SK, Tosteson TD, Weinstein JN. SPORT: Does incidental durotomy affect longterm outcomes in cases of spinal stenosis? Neurosurgery. 2011;76(Suppl:1):S57-63. discussion S63.

18. Deyo RA. Treatment of lumbar spinal stenosis: a balancing act. Spine J. 2010;10(7):625-7.

19. Department of Health. In. Canton of Zurich; 2013 [Personal Communication in April 2015]

20. Steurer J, Nydegger A, Held U, Brunner F, Hodler J, Porchet F, Min K, Mannion AF, Michel B. LumbSten: the lumbar spinal stenosis outcome study. BMC Musculoskelet Disord. 11:254.

21. Andreisek G, Deyo RA, Jarvik JG, Porchet F, Winklhofer SFX, Steurer J, Grp LW. Consensus conference on core radiological parameters to describe lumbar stenosis - an initiative for structured reporting. Eur Radiol. 2014;24(12):3224-32.

22. Stucki G, Liang MH, Fossel AH, Katz JN. Relative responsiveness of conditionspecific and generic health status measures in degenerative lumbar spinal stenosis. J Clin Epidemiol. 1995:48(11):1369-78.

23. Tuli SK, Yerby SA, Katz JN. Methodological approaches to developing criteria for improvement in lumbar spinal stenosis surgery. Spine (Phila Pa 1976). 2006:31(11):1276-80

24. Zucherman JF, Hsu KY, Hartjen CA, Mehalic TF, Implicito DA, Martin MJ, Johnson DR, 2nd, Skidmore GA, Vessa PP, Dwyer JW, et al. A multicenter, prospective, randomized trial evaluating the X STOP interspinous process 
decompression system for the treatment of neurogenic intermittent claudication: two-year follow-up results. Spine (Phila Pa 1976). 2005;30(12):1351-8.

25. Hansraj KK, O'Leary PF, Cammisa Jr FP, Hall JC, Fras Cl, Cohen MS, Dorey FJ. Decompression, fusion, and instrumentation surgery for complex lumbar spinal stenosis. Clin Orthop Relat Res. 2001;384:18-25.

26. Fokter SK, Yerby SA. Patient-based outcomes for the operative treatment of degenerative lumbar spinal stenosis. Eur Spine J. 2006;15(11):1661-9.

27. Hinz A, Klaiberg A, Brahler E, Konig HH. The Quality of Life Questionnaire EQ-5D: modelling and norm values for the general population. Psychother Psychosom Med Psychol. 2006;56(2):42-8.

28. Roland M, Morris R. A study of the natural history of low-back pain. Part II: development of guidelines for trials of treatment in primary care. Spine (Phila Pa 1976). 1983;8(2):145-50.

29. Miller MD, Paradis CF, Houck PR, Mazumdar S, Stack JA, Rifai AH, Mulsant B, Reynolds CF. Rating chronic medical illness burden in geropsychiatric practice and research - application of the Cumulative Illness Rating-Scale. Psychiat Res. 1992;41(3):237-48.

30. Zigmond AS, Snaith RP. The hospital anxiety and depression scale. Acta Psychiat Scand. 1983;67(6):361-70.

31. Crawford JR, Henry JD, Crombie C, Taylor EP. Normative data for the HADS from a large non-clinical sample. Brit J Clin Psychol. 2001:40:429-34.

32. R Core Team. R: A Language and Environment for Statistical Computing. Vienna: R Foundation for Statistical Computing; 2013. http://www.R-project.org/.

33. Stromqvist $F$, Jonsson B, Stromqvist B. Dural lesions in lumbar disc herniation surgery: incidence, risk factors, and outcome. Eur Spine J. 2010;19(3):439-42.

34. Sin AH, Caldito G, Smith D, Rashidi M, Willis B, Nanda A. Predictive factors for dural tear and cerebrospinal fluid leakage in patients undergoing lumbar surgery. J Neurosurg Spine. 2006;5(3):224-7.

35. Wu AS, Griebel RW, Meguro K, Fourney DR. Spinal subdural empyema after a dural tear. Case report. Neurosurg Focus. 2004;17(6):E10.

36. Goodkin R, Laska LL. Unintended "incidental" durotomy during surgery of the lumbar spine: medicolegal implications. Surg Neurol. 1995;43(1):4-12. discussion 12-14.

37. Aalto TJ, Malmivaara A, Kovacs F, Herno A, Alen M, Salmi L, Kroger H, Andrade J, Jimenez R, Tapaninaho A, et al. Preoperative predictors for postoperative clinical outcome in lumbar spinal stenosis - Systematic review. Spine. 2006:31(18):E648-63.

38. McKillop AB, Carroll L, Battie MC. Depression as a prognostic factor of lumbar spinal stenosis: a systematic review. Spine J. 2014;14(5):837-46.

\section{Submit your next manuscript to BioMed Central and we will help you at every step:}

- We accept pre-submission inquiries

- Our selector tool helps you to find the most relevant journal

- We provide round the clock customer support

- Convenient online submission

- Thorough peer review

- Inclusion in PubMed and all major indexing services

- Maximum visibility for your research

Submit your manuscript at www.biomedcentral.com/submit

) Biomed Central 